\title{
Increased Occurrence of PTSD Symptoms in Adolescents with Major Depressive Disorder Soon After the Start of the COVID-19 Outbreak in China: a Cross-Sectional Survey
}

\author{
Hang Zhang \\ Sichuan University West China Hospital \\ Hanmei Xu \\ Sichuan University West China Hospital \\ Lijuan Huang \\ Sichuan University West China Hospital \\ Xiaolan Wang \\ Sichuan University West China Hospital

\section{Xiaowei Tang} \\ Sichuan University West China Hospital \\ Yanping Wang \\ Sichuan University West China Hospital \\ Fang Deng \\ Sichuan University West China Hospital \\ Wo Wang \\ University-Town Hospital of Chongqing Medical University \\ Yuanmei Tao \\ Sichuan University West China Hospital \\ Li Yin ( $\nabla$ yli009@163.com) \\ West China Hospital of Sichuan University https://orcid.org/0000-0002-7448-0284
}

\author{
Research article \\ Keywords: COVID-19, PTSD, MDD, adolescents, CRIES-13 \\ Posted Date: February 1st, 2021 \\ DOI: https://doi.org/10.21203/rs.3.rs-179625/v1 \\ License: @ (i) This work is licensed under a Creative Commons Attribution 4.0 International License. Read Full License
}

Version of Record: A version of this preprint was published at BMC Psychiatry on August 9th, 2021. See the published version at https://doi.org/10.1186/s12888-021-03400-1. 


\section{Abstract}

Objective

The Coronavirus Disease 2019 (COVID-19) pandemic continues to threaten the physical and mental health of people across the world. This study aimed to understand the psychological impact of this disease on adolescents with major depressive disorder (MDD) at one month after the start of the outbreak in China.

Methods

Using the Children's Impact of Event Scale (CRIES-13) questionnaire, we investigated the occurrence of posttraumatic stress disorder (PTSD) in two groups of adolescents: MDD patients who were in stable condition with antidepressant therapy and healthy controls. Total scores and factor subscores were compared between the two groups and subgroups stratified by sex and school grade. Logistic regression was used to identify variables associated with high total CRIES13 scores.

Results

Compared to controls $(n=107)$, the MDD group $(n=90)$ had higher total CRIES-13 scores and a higher proportion with a total score $\geq 30$. They also had a lower intrusion subscore and a higher arousal subscore. In the MDD group, males and females did not differ significantly in total CRIES-13 scores or factor subscores, but junior high school students had higher avoidance subscores than senior high school students. Logistic regression showed high total CRIES-13 scores to be associated with MDD and the experience of "flashbacks" or avoidance of traumatic memories associated with COVID-19.

Conclusions

It is crucial to understand the psychological impact of COVID-19 on adolescents with MDD in China, especially females and junior high school students. Longterm monitoring of adolescents with a history of mental illness is required to further understand these impacts.

Trial registration

ChiCTR, ChiCTR2000033402, Registered 31 May 2020, http://www.chictr.org.cn/index.aspx

\section{Introduction}

Over the last several months, the COVID-19 pandemic has become the source of enormous stress for people across the world [1-4]. Studies show that individuals who experience such stressful events are more likely to suffer from depression and experience symptoms of posttraumatic stress disorder (PTSD) [5-7]. Compared to adults, adolescents are at higher risk of mental illness after disasters [8]. Therefore, it is important not to overlook the mental health of children and adolescents [9], especially because it could lead to an increased risk of psychiatric disease in adulthood [10].

Psychiatric history and mental illness have been associated with an increased occurrence of PTSD symptoms in the young adults aged 18-21 years old [11]. However, very few cross-sectional studies have addressed the association between pre-trauma mental illness and PTSD. In this study, we investigated the psychological impact of the COVID-19 outbreak on adolescents suffering from major depressive disorder (MDD) in China. We are not aware of any other cross-sectional studies on the occurrence of PTSD symptoms in MDD adolescents during the COVID-19 outbreak.

\section{Methods}

\section{Study subjects}

The results described here were obtained within the context of a larger, prospective cohort study. The study was approved by the Ethics Committee of the West China Hospital of Sichuan University, and registered in the Chinese Clinical Trail Registry (ChiCTR2000033402). Written informed consent was obtained from all participants and their guardians.

Adolescents aged 12-18 years and diagnosed independently by two senior psychiatrists at our hospital with drug naïve, first-episode MDD according to Diagnostic and Statistical Manual of Mental Disorders IV (DSM-IV) were consecutively recruited from June 2019 to the time point we did this survey (February 2020). All adolescents are right-handed, primary school education or above, judged by imaging physician that there is no structural abnormality of the brain, can understand the content of the scale, has not received electrical convulsive therapy, has no physical illness and has not taken any other drugs recently. Before the administration of stable antidepressant therapy, we evaluated the severity of depression symptoms using the Chinese version of Beck Depression Inventory-II (BDI-II) [12]. Age- and sex-matched junior and senior school students without COVID-19 (based on our self-report general information form) were enrolled as healthy controls. We excluded all the participants with a history of substance abuse, as well as those suffering from severe physical and mental illnesses, including Axis I and Axis II disorders based on the DSM-IV. Nearly all subjects came from Sichuan province in China.

\section{Data collection}

Between 17 February and 23 February, approximately one month after the outbreak of COVID-19 in China, we collected demographic data using a general information form that we developed, as well as psychopathological data using the Chinese version of the Children's Revised Impact of Event Scale (CRIES-13) questionnaire [13]. 
The CRIES-13 was used as a brief self-rating scale for children $\geq 8$ years old. The degree of each stressful symptoms in the last 2 weeks was recorded to 4 grades (not at all, rarely, sometimes, often), respectively scored $0,1,3,5$ points. There was no reverse entry, and the three factors were intrusion (item 1,4,8,9), avoidance (item $2,6,7,10$ ), and high arousal (item $3,5,11,12,13$ ), respectively corresponding to the three symptom groups of B (re-experience), C (avoidance), and D (high arousal) in the DSM-IV diagnostic criteria for PTSD. The severity of the psychological impact caused by a stressful event can be measured using total CRIES-13 scores ranged $0-65$ points and a total score $\geq 30$ indicates severe psychological stress. According to the preliminary investigation, the Cronbach number of CRIES-13 was 0.81 , the re-test reliability was 0.79 , and the three-factor structure was stable, which confirmed that the table was a good screening tool for assessing the degree of stress response after traumatic events experienced by children[14-16]. All the questionnaires were distributed via WeChat ensured the responses of participants were anonymous to others but can only be seen by the researchers. Additionally, we conducted telephone interviews and semi-structured mental health examinations based on the Kiddie Schedule for Affective Disorders and Schizophrenia-Present and Lifetime Version (KSADS-PL) [17]. All PTSD diagnoses were confirmed by two independent psychiatrists based on the DSM-IV.

\section{Statistical analysis}

Statistical analyses were performed using Statistical Product and Service Solutions (SPSS) 25.0 (IBM, Armonk, NY, USA), and the significance level was set at $a=0.05$. We analyzed participant data and compared CRIES-13 scores across groups using chi-squared, Mann-Whitney $\mathrm{U}, \mathrm{Kruskal}-\mathrm{Wallis} \mathrm{H}$, Student's $t$ or Fisher's exact tests as appropriate.

Bivariate logistic regression analysis was performed to assess the factors influencing the proportion of subjects with a total CRIES-13 score $\geq 30$. Participants were stratified into two groups: those with a total score $<30$ (CRIES-) and those with a total score $\geq 30$ (CRIES+). We considered the effects of group (MDD/control), sex (female/male), grade (senior/junior high school), and family structure (with single-parent family serving as reference in the regression). We also considered exposure to infection, which was defined as relatives with COVID-19 (yes/no), or as having family members who work at the frontline in medical facilities (yes/no). We included participants' responses to such questions as "How often do images associated with COVID-19 cross your mind?" and "How often do you have to stop yourself from thinking about COVID-19?" (those responding "not at all" served as reference in the regression).

\section{Results}

\section{Demographic characteristics}

Of the 95 patients and 120 controls initially enrolled, valid questionnaires were received from 90 patients and 107 controls (excluded controls who had undergone psychological counseling with underlying psychological problems and MDD patients who had not been treated). Most of the patients were receiving antidepressant medications at the start of the study, including sertraline (32 patients, $50-150 \mathrm{mg} /$ day), fluoxetine (7 patients, $20-40 \mathrm{mg} / \mathrm{day}$ ), escitalopram ( 20 patients, $10-20 \mathrm{mg} /$ day), venlafaxine (22 patients, $150-225 \mathrm{mg} /$ day), agomelatine (4 patients, 25-50 mg/day), and one patients were taking both sertraline (50 mg/day)and agomelatine $(25 \mathrm{mg} /$ day). Four patients were receiving psychotherapy instead of antidepressant medication.

The MDD group (72 females) consisted of 47 junior high school students and 43 senior high school students, while the control group (82 females) had 58 junior high school students and 49 senior high school students. Patients and controls differed significantly in family structure and occupation of parents, but not in sex ratio, age, school grade or exposure to infection (Table 1). 
Table 1

Demographic characteristics of adolescents with or without major depressive disorder, stratified by sex and school grade

\begin{tabular}{|c|c|c|c|c|c|c|c|c|c|c|c|c|c|c|}
\hline \multirow[b]{3}{*}{ Characteristic } & \multirow{3}{*}{$\begin{array}{l}\text { Total } \\
\text { MDD }^{1}\end{array}$} & \multirow[b]{3}{*}{ Control } & & & \multicolumn{6}{|c|}{ Stratified by sex } & \multicolumn{4}{|c|}{ Stratified by school grade } \\
\hline & & & & & \multicolumn{2}{|c|}{ Male $(n=43)$} & \multicolumn{2}{|c|}{ Female $(n=154)$} & & & \multicolumn{2}{|c|}{ Junior $(n=105)$} & \multicolumn{2}{|c|}{ Senior $(n=92)$} \\
\hline & & & & & MDD & Control & MDD & Control & & & MDD & Control & MDD & Control \\
\hline & $\begin{array}{l}(n= \\
90)\end{array}$ & $\begin{array}{l}(n= \\
107)\end{array}$ & $z / x^{2}$ & $\mathrm{p}$ & $\begin{array}{l}(n= \\
18)\end{array}$ & $\begin{array}{l}(n= \\
25)\end{array}$ & $\begin{array}{l}(n= \\
72)\end{array}$ & $\begin{array}{l}(n= \\
82)\end{array}$ & $H / t / x^{2}$ & $\mathrm{p}$ & $\begin{array}{l}(n= \\
47)\end{array}$ & $\begin{array}{l}(n= \\
58)\end{array}$ & $\begin{array}{l}(n= \\
43)\end{array}$ & $\begin{array}{l}(n= \\
49)\end{array}$ \\
\hline $\begin{array}{l}\text { Median age } \\
\text { (years) }\end{array}$ & 15 & 15 & -0.69 & 0.491 & 15.00 & 15.00 & 15.00 & 15.00 & 0.61 & 0.894 & 14.00 & 14.00 & 16.00 & 17.00 \\
\hline $\begin{array}{l}\text { Baseline } \mathrm{BDI}^{2} \\
\text { score }\end{array}$ & $\begin{array}{l}35.81 \\
\pm \\
11.79\end{array}$ & NA & & & $\begin{array}{l}33.33 \\
\pm 9.11\end{array}$ & NA & $\begin{array}{l}36.43 \\
\pm \\
12.35\end{array}$ & NA & -1.00 & 0.322 & $\begin{array}{l}37.65 \\
\pm \\
12.79\end{array}$ & NA & $\begin{array}{l}33.80 \\
\pm \\
10.38\end{array}$ & NA \\
\hline $\begin{array}{l}\text { Sex } \\
\text { (Male/Female) }\end{array}$ & $18 / 72$ & $25 / 82$ & 0.32 & 0.569 & & & & & & & $10 / 37$ & $15 / 43$ & $8 / 35$ & $10 / 39$ \\
\hline $\begin{array}{l}\text { Grade } \\
\text { (Junior/Senior) }\end{array}$ & $47 / 43$ & $58 / 49$ & 0.08 & 0.781 & $10 / 8$ & $15 / 10$ & $37 / 35$ & $43 / 39$ & 0.62 & 0.892 & NA & NA & NA & NA \\
\hline $\begin{array}{l}\text { Family } \\
\text { structure }\end{array}$ & & & 12.28 & 0.006 & & & & & & 0.075 & & & & \\
\hline Single parent & 13 & 8 & & & 1 & 2 & 12 & 6 & & & 6 & 4 & 7 & 4 \\
\hline Two parents & 34 & 36 & & & 6 & 10 & 28 & 26 & & & 17 & 18 & 17 & 18 \\
\hline $\begin{array}{l}\text { Multi- } \\
\text { generational }\end{array}$ & 19 & 46 & & & 5 & 10 & 14 & 36 & & & 9 & 25 & 10 & 21 \\
\hline Other & 24 & 17 & & & 6 & 3 & 18 & 14 & & & 15 & 11 & 9 & 6 \\
\hline $\begin{array}{l}\text { Occupation of } \\
\text { parents }\end{array}$ & & & & 0.035 & & & & & & 0.087 & & & & \\
\hline Medical staff & 2 & 1 & & & 0 & 1 & 2 & 0 & & & 1 & 1 & 1 & 0 \\
\hline Police & 1 & 1 & & & 0 & 0 & 1 & 1 & & & 0 & 1 & 1 & 0 \\
\hline Civil servant & 8 & 5 & & & 0 & 0 & 8 & 5 & & & 4 & 4 & 4 & 1 \\
\hline Teacher & 9 & 3 & & & 1 & 1 & 8 & 2 & & & 3 & 1 & 6 & 2 \\
\hline Freelancer & 14 & 20 & & & 6 & 6 & 8 & 14 & & & 7 & 11 & 7 & 9 \\
\hline Farmer & 1 & 9 & & & 0 & 3 & 1 & 6 & & & 0 & 4 & 1 & 5 \\
\hline Researcher & 2 & 0 & & & 1 & 0 & 1 & 0 & & & 2 & 0 & 0 & 0 \\
\hline Worker & 17 & 24 & & & 2 & 6 & 15 & 18 & & & 8 & 12 & 9 & 12 \\
\hline Self-employed & 19 & 31 & & & 5 & 7 & 14 & 24 & & & 12 & 17 & 7 & 14 \\
\hline Others & 17 & 13 & & & 3 & 1 & 14 & 12 & & & 10 & 7 & 7 & 6 \\
\hline \multicolumn{15}{|c|}{$\begin{array}{l}\text { Respondent has family members } \\
\text { who are }\end{array}$} \\
\hline $\begin{array}{l}\text { Infected } \\
\text { (Yes/No) }\end{array}$ & $0 / 90$ & $4 / 103$ & & 0.127 & $0 / 18$ & $0 / 25$ & $0 / 72$ & $4 / 78$ & & 0.249 & $0 / 47$ & $2 / 56$ & $0 / 43$ & $2 / 47$ \\
\hline $\begin{array}{l}\text { Frontline } \\
\text { health worker } \\
\text { (Yes/No) }\end{array}$ & $3 / 87$ & $3 / 104$ & & 1.000 & $0 / 18$ & $0 / 25$ & $3 / 69$ & $3 / 79$ & & 0.925 & $2 / 45$ & $1 / 57$ & $1 / 42$ & $2 / 47$ \\
\hline
\end{tabular}

Values are $\mathrm{n}$ or mean $\pm \mathrm{SD}$, unless otherwise noted.

${ }^{1}$ MDD, major depressive disorder

${ }^{2}$ BDI, Beck Depression Inventory

The baseline mean BDI score in the MDD group (before treatment with antidepressants) was $35.81 \pm 11.79$. We found no significant difference in baseline BDI scores between male and female patients $(t=-1.00, p=0.322)$, or between junior and senior high school students $(t=1.56, p=0.123)$. They were all received antidepressant therapy at least 6 weeks and based on the BDI scores after treatments, 8 of the patients were remission on the MDD (BDI-II score $\leq 9$ ) [18].

\section{CRIES-13 scores}


The MDD group had significantly higher total CRIES-13 scores than controls ( 23.5 vs $21, z=-2.14, p=0.033)$, as well as a higher proportion of participants with a total score $\geq 30\left(34.4 \%\right.$ vs $\left.15.9 \%,{ }^{2}=9.13, p=0.003\right)$. Patients also had a significantly lower intrusion subscore $(7 \mathrm{vs} 9, z=-2.17, p=0.030)$ and higher arousal subscore ( 13 vs $8, z=-6.39, p<0.001)$ (Table 2 ).

Table 2

CRIES-13 scores of adolescents with or without major depressive disorder (MDD)

\begin{tabular}{|c|c|c|c|c|c|}
\hline & Total & MDD & Controls & \multirow[t]{2}{*}{$z / x^{2}$} & \multirow[t]{2}{*}{$p$} \\
\hline & $(n=197)$ & $(n=90)$ & $(n=107)$ & & \\
\hline \multicolumn{6}{|l|}{ Median scores } \\
\hline Total & 22.00 & 23.50 & 21.00 & -2.14 & 0.033 \\
\hline Intrusion factor & 8.00 & 7.00 & 9.00 & -2.17 & 0.030 \\
\hline Avoidance factor & 3.00 & 3.50 & 3.00 & -0.14 & 0.886 \\
\hline Arousal factor & 10.00 & 13.00 & 8.00 & -6.39 & $<0.001$ \\
\hline \multicolumn{6}{|c|}{ Distribution by total score, n (\%) } \\
\hline$\varangle 30$ & $149(75.6)$ & $59(65.6)$ & $90(84.1)$ & 9.13 & 0.003 \\
\hline$\geq 30$ & $48(24.4)$ & $31(34.4)$ & $17(15.9)$ & & \\
\hline
\end{tabular}

Male and female patients did not differ significantly in total scores, factor subscores, or proportion of participants with a total score $\geq 30$ (Table 3 ). Among controls, however, females had higher total scores (22.5 vs $16, z=-2.89, p=0.004)$ and arousal subscores $(8$ vs $4, z=-3.79, p<0.001)$ than males.

Table 3

CRIES-13 scores of adolescents with or without major depressive disorder (MDD), stratified by sex

\begin{tabular}{|c|c|c|c|c|c|c|c|c|}
\hline & MDD & & & & Controls & & & \\
\hline & Male & Female & \multirow[t]{2}{*}{$z / x^{2}$} & \multirow[t]{2}{*}{$\mathrm{p}$} & Male & Female & \multirow[t]{2}{*}{$z / x^{2}$} & \multirow[t]{2}{*}{$\mathrm{p}$} \\
\hline & $(n=18)$ & $(n=72)$ & & & $(n=25)$ & $(n=82)$ & & \\
\hline \multicolumn{9}{|l|}{ Median scores } \\
\hline Total & 22.00 & 25.00 & -0.09 & 0.928 & 16.00 & 22.50 & -2.89 & 0.004 \\
\hline Intrusion factor & 4.50 & 8.00 & -0.81 & 0.421 & 7.00 & 9.50 & -1.83 & 0.068 \\
\hline Avoidance factor & 4.00 & 3.00 & -0.69 & 0.488 & 3.00 & 3.50 & -0.47 & 0.637 \\
\hline Arousal factor & 13.00 & 13.00 & -0.20 & 0.840 & 4.00 & 8.00 & -3.79 & $<0.001$ \\
\hline \multicolumn{9}{|c|}{ Distribution of total scores, $\mathrm{n}(\%)$} \\
\hline$\llbracket 30$ & $12(66.7)$ & $47(65.3)$ & \multirow[t]{2}{*}{0.01} & \multirow[t]{2}{*}{0.912} & $21(84)$ & $69(84.1)$ & & \multirow[t]{2}{*}{1.000} \\
\hline$\geq 30$ & $6(33.3)$ & $25(34.7)$ & & & $4(16)$ & 13 (15.9) & & \\
\hline
\end{tabular}

Among either patients or controls, the proportion of participants with a total score $\geq 30$ was not significantly different between junior high school or senior high school students (Table 4). Among patients, junior high school students had significantly higher avoidance subscores than senior high school students (5 vs $2, z=-2.20, p=0.028)$. Among controls, senior high school students had higher total scores (24 vs $19, z=-2.06, p=0.040)$ and intrusion subscores $(10$ vs 8 , $z=-2.14, p=0.033)$ than junior high school students. 
Table 4

CRIES-13 scores of adolescents with and without major depressive disorder (MDD), stratified by school grade

\begin{tabular}{|c|c|c|c|c|c|c|c|c|}
\hline & MDD & & & & Controls & & & \\
\hline & Junior high & Senior high & $z / x^{2}$ & $\mathrm{p}$ & Junior high & Senior high & $z / x^{2}$ & $\mathrm{p}$ \\
\hline & $(n=47)$ & $(n=43)$ & & & $(n=58)$ & $(n=49)$ & & \\
\hline \multicolumn{9}{|l|}{ Median scores } \\
\hline Total & 26.00 & 22.00 & -0.92 & 0.357 & 19.00 & 24.00 & -2.06 & 0.040 \\
\hline Intrusion factor & 6.00 & 7.00 & -0.02 & 0.981 & 8.00 & 10.00 & -2.14 & 0.033 \\
\hline Avoidance factor & 5.00 & 2.00 & -2.20 & 0.028 & 3.00 & 3.00 & -0.17 & 0.862 \\
\hline Arousal factor & 13.00 & 13.00 & -0.55 & 0.579 & 7.00 & 8.00 & -1.95 & 0.052 \\
\hline \multicolumn{9}{|c|}{ Distribution of total scores, $\mathrm{n}(\%)$} \\
\hline 『30 & $27(57.4)$ & $32(74.4)$ & 2.87 & 0.091 & $52(89.7)$ & $38(77.6)$ & 2.91 & 0.088 \\
\hline$\geq 30$ & $20(42.6)$ & $11(25.6)$ & & & $6(10.3)$ & $11(22.4)$ & & \\
\hline
\end{tabular}

\section{PTSD diagnosis}

Two clinicians performed mental health examinations of all the subjects who had total CRIES-13 scores $\geq 30$ ( 31 patients and 17 controls). Eleven patients were determined by KSADS to have experienced PTSD before the COVID-19 outbreak, while none of the controls was diagnosed with PTSD.

\section{Factors influencing total CRIES-13 scores}

Logistic regression identified the following factors as influencing total CRIES-13 scores: group, responses to CRIES-13 questions such as COVID-19 images cross one's mind, and having to stop oneself from thinking about the pandemic (Table 5). The model was able to classify $85.3 \%$ of participants into correct CRIES- and CRIES + groups, corresponding to sensitivity, $60.4 \%$; specificity, $93.3 \%$; positive predictive value,74.4\%; and negative predictive value, $88 \%$ (Table 6).

Table 5

Logistic regression to identify related to a total CRIES-13 score of at least $30(n=197)$

\begin{tabular}{|c|c|c|c|c|c|}
\hline Variable & B & SE & Wald chi-square & $\mathrm{OR}(95 \% \mathrm{Cl})$ & $p$ \\
\hline Group (Patient/Control) & 2.92 & 0.63 & 21.39 & $18.54(5.38-63.88)$ & $<0.001$ \\
\hline Sex (Female/Male) & 0.49 & 0.64 & 0.60 & $1.63(0.47-5.68)$ & 0.441 \\
\hline Grade (Senior high/Junior high school) & 0.43 & 0.50 & 0.75 & $1.54(0.58-4.07)$ & 0.386 \\
\hline Family structure ${ }^{1}$ & & & 4.64 & & 0.200 \\
\hline Two parents & 0.01 & 0.80 & 0.00 & $1.01(0.21-4.86)$ & 0.990 \\
\hline Multi-generational & 1.30 & 0.86 & 2.28 & $3.66(0.68-19.69)$ & 0.131 \\
\hline Other & 0.13 & 0.92 & 0.02 & $1.14(0.19-6.86)$ & 0.885 \\
\hline Relative(s) infected with COVID-19 (Yes/No) & 0.98 & 1.49 & 0.44 & $2.68(0.14-49.56)$ & 0.509 \\
\hline Family member works at frontline (Yes/No) & -0.66 & 1.79 & 0.13 & $0.52(0.02-17.43)$ & 0.714 \\
\hline How often do images associated with COVID-19 cross your mind? ${ }^{2}$ & & & 27.16 & & $<0.001$ \\
\hline Rarely & 1.64 & 1.17 & 1.96 & $5.16(0.52-51.43)$ & 0.162 \\
\hline Sometimes & 4.01 & 1.16 & 11.96 & $54.89(5.67-531.26)$ & 0.001 \\
\hline Often & 5.81 & 1.34 & 18.96 & $333.93(24.42-4567.19)$ & $<0.001$ \\
\hline How often do you have to stop yourself from thinking about COVID-1 & & & 21.97 & & $<0.001$ \\
\hline Rarely & 1.66 & 0.65 & 6.60 & $5.24(1.48-18.57)$ & 0.010 \\
\hline Sometimes & 3.36 & 0.74 & 20.83 & $28.81(6.81-122.01)$ & $<0.001$ \\
\hline Often & 3.38 & 1.10 & 9.56 & $29.23(3.44-248.23)$ & 0.002 \\
\hline \multicolumn{6}{|c|}{${ }^{1}$ Respondents answering "single-parent family" served as the reference group } \\
\hline
\end{tabular}


Table 6

Classification table of the logistic regression

\begin{tabular}{|llll|}
\hline \multirow{2}{*}{ Observed } & \multicolumn{2}{l}{ Predicted by combination of all factors } & \% correct \\
\cline { 2 - 4 } & CRIES-13 - & CRIES-13 + & \\
\hline CRIES-13 - & 139 & 10 & 63.3 \\
\hline CRIES-13 + & 19 & 29 & 85.3 \\
\hline Overall & & & 85.4 \\
\hline CRIES-13 -: respondents with total CRIES-13 scores $\llbracket 30$, CRIES-13 +: respondents with total CRIES-13 scores $\geq 30$ \\
\hline
\end{tabular}

\section{Discussion}

In this study, we examined and compared the effects of the COVID-19 outbreak on the mental health of Chinese adolescents with or without MDD. We found that the MDD group had higher total CRIES-13 scores, as well as a higher proportion of participants with a total score $\geq 30$ than healthy controls. These results indicate that early in the COVID-19 outbreak, adolescents with MDD were more likely than adolescents without MDD to experience severe psychological stress and symptoms of PTSD. Similar results were observed in United States military personnel deployed in the conflicts in Iraq and Afghanistan and patients with neurotic disorders after the Great East Japan Earthquake on 11 March 2011[19, 20] .

Our study found higher arousal and lower intrusion subscores among patients than controls based on the CRIES-13. The symptoms of arousal observed in the MDD group were inability to concentrate, irritability, insomnia, as well as increased vigilance and fear. This could be due to higher levels of brain arousaland hyper-stable regulation caused by the hyperactivity of the locus coeruleus in the central noradrenergic system[21, 22] [22-23]. The hyper-stable regulation mode can prevent MDD patients from reducing arousal in order to sleep or regulate diurnal variation in mood [23][24].The lower intrusion levels in MDD patients may be a result of antidepressant treatment, which can decrease the response to psychological stimuli by dampening activation of the amygdala[24, 25] [25-26].The amygdala is activated when the brain encodes non-spontaneous, intrusive memories, such as "flashbacks" of traumatic events[26, 27] [2728]. Further studies should examine how arousal and intrusion levels influence risk of PTSD symptoms in adolescents during the COVID-19 outbreak.

Age is a crucial factor associated with psychological stress caused by disasters[28, 29] [37-38]. In our study, junior high school students with MDD showed higher avoidance levels than senior high school students. This may reflect higher "distractibility" and greater tendency to apply maladaptive coping strategies among younger students, who may therefore be more vulnerable to negative effects of stressful situations [30] [39]. So we should focus on intervention of MDD patients in junior high students and try to explore how age factor affect the avoidance level of MDD patients.

Studies have also reported sex differences in the severity of posttraumatic stress symptoms [31, 32] [29-30]. After the 5.12 Wenchuan earthquake in China, women were at higher risk of PTSD [32], and this increased risk of PTSD may be associated with biological, environmental and social factors [33] [31].Fluctuations in ovarian hormone levels can alter sensitivity to emotional stimuli at certain stages of the menstrual cycle, which could in turn lead to an increased susceptibility to mental illness [34].A study on adult women showed that fear associated with the COVID-19 outbreak can lead to higher arousal symptoms [35]. Among individuals with PTSD, women show greater reactivity than men in the fear and arousal network in the ventral region of the brainstem [36] [34]. These reports are consistent with our findings that female controls had higher total CRIES-13 scores and arousal subscores than male controls. However, we observed no significant sex differences in total scores or factor subscores among MDD patients. MDD has been associated with sensitization of the neurotransmitter and neuroendocrine systems, resulting in higher reactivity to stress [37], but whether women with MDD are more vulnerable to external stress than men with MDD is unknown. We speculate that the MDD-induced shift in hormone levels may mask sex differences in reactivity to external stimuli.

Adolescents can recover from the effects of their maladaptive cognitive style after disasters sooner than adults can [38]. Nevertheless, there is a positive correlation between history of pre-traumatic mental illness and post-traumatic stress symptoms in both adults and adolescents [38, 39], and our results with adolescents show that larger proportions of patients than controls had PTSD symptoms and total CRIES- 13 scores $\geq 30$. Therefore, the post-disaster mental status of adolescents with MDD should be carefully monitored to avoid the risk of PTSD. A hallmark of PTSD is the transition from re-experiencing to avoiding memories associated with trauma [26]. Consistent with other studies on the role of avoidance symptoms [40, 41], we observed a significant association between total CRIES-13 scores and responses to questions such as" How often do images associated with COVID-19 cross your mind?" and "How often do you have to stop yourself from thinking about COVID-19?" The mechanisms of how these factors associated with high risk of PTSD occurrence can be studied in the future.

Our cross-sectional study provides what appears to be the first evidence that COVID-19 is having a particularly strong psychological impact on adolescents with MDD, especially females and junior high school students. Whether our findings can be generalized to adolescents outside Sichuan province in China needs to be confirmed. Future work should examine potential influence of antidepressant therapy on the vulnerability of adolescents to COVID-19 stress. Based on the mental health examinations that we conducted on a subset of patients and controls who scored at least 30 on CRIES-13, we did not detect anyone with PTSD that could be attributed to the COVID-19 outbreak. This may be because our study was conducted only one month after the outbreak began in China, and because of the containment measures implemented rapidly by the government. Our continuing analysis of these patients and controls as part of our larger prospective cohort study (ChiCTR2000033402) may detect an association between COVID-19 and PTSD among adolescents with or without MDD. This may help identify adolescents who require psychological and clinical intervention.

\section{Abbreviations}




\section{BDI-II}

Beck Depression Inventory-II

COVID-19

Coronavirus Disease 2019

CRIES-13

the Children's Impact of Event Scale questionnaire

\section{DSM-IV}

the Diagnostic and Statistical Manual of Mental Disorders IV

KSADS-PL

Kiddie Schedule for Affective Disorders and Schizophrenia-Present and Lifetime Version

MDD

Major Depressive Disorder

PTSD

Post-Traumatic Stress Disorder

SPSS

Statistical Product and Service Solutions

\section{Declarations}

\section{Acknowledgments}

We would like to thank our colleagues and volunteers for their support.

\section{Funding}

This work was supported by the National Nature Science Foundation of China (81801357), the Science and Technology Education Program of the Sichuan Province (2020JDKP0013, 2020YFS0259), and the Chengdu Key Technology R\&D Program (2019-YF05-00284-SN). The above mentioned funding bodies had no further role in the study design, collection, analysis and interpretation of data; in the writing of the report; and in the decision to submit the paper for publication.

\section{Availability of data and material}

The data that support the findings of this study are available on request from the corresponding author (Li Yin, yli009@163.com). The data are not publicly available due to privacy or ethical restrictions.

\section{Ethics approval and consent to participate}

This study was approved by the Ethics Committee of West China Hospital of Sichuan University. The research had been performed in accordance with the Declaration of Helsinki. Written informed consents had been attained from all the participants and their guardians based on the principle of self-determination. The participants'rights were fully respected and preserved in the whole process of this study.

\section{Competing interests}

The authors declare that they have no competing interests.

\section{Consent for publication}

Not applicable.

\section{Authors' contributions}

Methodology, Zhang Hang and Xu Hanmei; investigation, Zhang Hang, Xu Hanmei, Huang Lijuan, Wang Xiaolan, Tang Xiaowei, Wang Yanping, Deng Fang, Wo Wang, Tao Yuanmei and Yin Li.

writing-original draft preparation, Zhang Hang and Xu Hanmei ; writing-review and editing, Zhang Hang and Yin li; project administration, Yin Li; funding acquisition, Yin li

\section{Authors' Information}

Hang Zhang, Email: 860930225@qq.com

Hanmei Xu, Email: 874062001@qq.com

Lijuan Huang, Email: 20370587@qq.com

Xiaolan Wang, Email: 1253874223@qq.com 
Xiaowei Tang, Email: 454531419@qq.com

Yanping Wang, Email: 449573091@qq.com

Fang Deng, Email: 916542248@qq.com

Wo Wang, Email: 157521663@qq.com

Yuanmei Tao, Email: 923735020@qq.com

Li Yin, Email: yli009@163.com

Author details

${ }^{1}$ Mental Health Center, West China Hospital of Sichuan University, No. 28 Dianxin South Street, Chengdu, Sichuan 610041, China; ${ }^{2}$ The Fourth People's Hospital of Chengdu, Chengdu, Sichuan 610036, China; ${ }^{3}$ University-Town Hospital of Chongqing Medical University, 55 University Town Middle Road, Shapingba District, Chongqing 400000, China; ${ }^{4}$ Frontiers Science Center for Disease-related Molecular Network, Chengdu, Sichuan 610041, China.

\section{References}

1. Liu CH, Zhang E, Wong GTF, Hyun S, Hahm HC: Factors associated with depression, anxiety, and PTSD symptomatology during the COVID-19 pandemic: Clinical implications for U.S. young adult mental health. Psychiatry research 2020, 290:113172.

2. Fawaz M, Samaha A: COVID-19 quarantine: Post-traumatic stress symptomatology among Lebanese citizens. The International journal of social psychiatry 2020, 66(7):666-674.

3. Tang W, Hu T, Hu B, Jin C, Wang G, Xie C, Chen S, Xu J: Prevalence and correlates of PTSD and depressive symptoms one month after the outbreak of the COVID-19 epidemic in a sample of homequarantined Chinese university students. Journal of Affective Disorders 2020, $274: 1-7$.

4. Lai J, Ma S, Wang Y, Cai Z, Hu J, Wei N, Wu J, Du H, Chen T, Li R et al: Factors Associated With Mental Health Outcomes Among Health Care Workers Exposed to Coronavirus Disease 2019. Jama Network Open 2020, 3(3).

5. Stander VA, Thomsen CJ, Highfill-McRoy RM: Etiology of depression comorbidity in combat-related PTSD: a review of the literature. Clinical psychology review 2014, 34(2):87-98.

6. Breslau N: The epidemiology of trauma, PTSD, and other posttrauma disorders. Trauma, violence \& abuse 2009, 10(3):198-210.

7. Brady KT, Killeen TK, Brewerton T, Lucerini S: Comorbidity of psychiatric disorders and posttraumatic stress disorder. Journal of Clinical Psychiatry 2000, 61:22-32.

8. Kolaitis G, Kotsopoulos J, Tsiantis J, Haritaki S, Rigizou F, Zacharaki L, Riga E, Augoustatou A, Bimbou A, Kanari N et al: Posttraumatic stress reactions among children following the Athens earthquake of September 1999. European child \& adolescent psychiatry 2003, 12(6):273-280.

9. Danese A, Smith P, Chitsabesan P, Dubicka B: Child and adolescent mental health amidst emergencies and disasters. Br J Psychiatry 2020, 216(3):159162.

10. Xu W, Yuan G, Liu Z, Zhou Y, An Y: Prevalence and predictors of PTSD and depression among adolescent victims of the Summer 2016 tornado in Yancheng City. Archives of psychiatric nursing 2018, 32(5):777-781.

11. Frazier PA, Gavian M, Hirai R, Park C, Tennen H, Tomich P, Tashiro T: Prospective Predictors of Posttraumatic Stress Disorder Symptoms: Direct and Mediated Relations. Psychol Trauma 2011, 3(1):27-36.

12. Yang WH, Liu SL, Zhou T, Peng F, Liu XM, Li L, Yang CM, Liu HH, Yi JY: Reliability and Validity of Chinese Version of the Beck Depression Inventory- in Chinese Adolescents. Chinese Journal of Clinical Psychology 2014, 22(2):240-245. (in Chinese)

13. Situ MJ, Huang Y, Zhang Y, Fang H, Wang D, Jing LS, Chen T, Qiu CJ, Sun XL, Zhang W: Psychometric properties of the Children's Revised Impact of Event Scale in children from earthquake affected areas. Chinese Journal of Psychiatry 2009, 42 (4):235-239. (in Chinese)

14. Perrin S, Meiser-Stedman R, Smith P: The Children's Revised Impact of Event Scale (CRIES): Validity as a screening instrument for PTSD. Behav Cognit Psychther 2005, 33(4):487-498.

15. Giannopoulou L, Smith P, Ecker C, Strouthos M, Dikaiakou A, Yule W: Factor structure of the Children's Revised Impact of Event Scale (CRIES) with children exposed to earthquake. Pers Individ Differ 2006, 40(5):1027-1037.

16. Smith P, Perrin S, Dyregrov A, Yule W: Principal components analysis of the impact of event scale with children in war. Pers Individ Differ 2003, 34(2):315322.

17. Kaufman J, Birmaher B, Brent D, Rao U, Flynn C, Moreci P, Williamson D, Ryan N: Schedule for Affective Disorders and Schizophrenia for School-Age Children Present and Lifetime version (K-SADS-PL): Initial reliability and validity data. J Am Acad Child Adolesc Psychiatr 1997, 36(7):980-988.

18. Freedland KE, Carney RM, Rich MW, Steinmeyer BC, Rubin EH: Cognitive Behavior Therapy for Depression and Self-Care in Heart Failure Patients: A Randomized Clinical Trial. JAMA Internal Medicine 2015, 175(11):1773-1782.

19. Sandweiss DA, Slymen DJ, Leardmann CA, Smith B, White MR, Boyko EJ, Hooper TI, Gackstetter GD, Amoroso PJ, Smith TC et al: Preinjury psychiatric status, injury severity, and postdeployment posttraumatic stress disorder. Arch Gen Psychiatry 2011, 68(5):496-504.

20. Inoue K, Inoue K, Suda S, Shioda K, Kobayashi T, Kishi K, Kato S: Differences in vulnerability to traumatic stress among patients with psychiatric disorders: One-year follow-up study after the Great East Japan Earthquake. Psychiatry Clin Neurosci 2015, 69(9):587-595.

Page $9 / 10$ 
21. Schmidt FM, Sander C, Dietz ME, Nowak C, Schr?der T, Mergl R, Sch?nknecht P, Himmerich H, Hegerl U: Brain arousal regulation as response predictor for antidepressant therapy in major depression. Sci Rep 2017, 7:45187.

22. Hegerl U, Wilk K, Olbrich S, Schoenknecht P, Sander C: Hyperstable regulation of vigilance in patients with major depressive disorder. World J Biol Psychiatry 2012, 13(6):436-446.

23. Schmidt FM, Pschiebl A, Sander C, Kirkby KC, Thormann J, Minkwitz J, Chittka T, Weschenfelder J, Holdt LM, Teupser D et al: Impact of Serum Cytokine Levels on EEG-Measured Arousal Regulation in Patients with Major Depressive Disorder and Healthy Controls. Neuropsychobiology 2016, 73(1):1-9.

24. Windischberger C, Lanzenberger R, Holik A, Spindelegger C, Stein P, Moser U, Gerstl F, Fink M, Moser E, Kasper S: Area-specific modulation of neural activation comparing escitalopram and citalopram revealed by pharm aco-fMRI: a randomized cross-over study. Neuroimage 2010, 49(2):1161-1170.

25. Chen YT, Huang MW, Hung IC, Lane HY, Hou CJ: Right and left amygdalae activation in patients with major depression receiving antidepressant treatm ent, as revealed by fMRI. Behav Brain Funct 2014, 10(1):36.

26. Brewin CR, Dalgleish T, Joseph S: A dual representation theory of posttraumatic stress disorder. Psychological review 1996, 103(4):670-686.

27. Bourne C, Mackay CE, Holmes EA: The neural basis of flashback formation: the impact of viewing trauma. Psychological medicine 2013, 43(7):15211532.

28. Morris MC, Kouros CD, Hellman N, Rao U, Garber J: Two prospective studies of changes in stress generation across depressive episodes in adolescents and emerging adults. Dev Psychopathol 2014, 26(4 Pt 2):1385-1400.

29. Norris FH, Friedman MJ, Watson PJ, Byrne CM, Diaz E, Kaniasty K: 60,000 disaster victims speak: Part I. An empirical review of the empirical literature, 1981-2001. Psychiatry 2002, 65(3):207-239.

30. Hampel P, Petermann F: Age and gender effects on coping in children and adolescents. Journal of Youth and Adolescence 2005, 34(2):73-83.

31. Alisic E, Jongmans MJ, van Wesel F, Kleber RJ: Building child trauma theory from longitudinal studies: a meta-analysis. Clin Psychol Rev 2011, 31(5):736747.

32. Ma X, Liu X, Hu X, Qiu C, Wang Y, Huang Y, Wang Q, Zhang W, Li T: Risk indicators for post-traumatic stress disorder in adolescents exposed to the 5.12 Wenchuan earthq uake in China. Psychiatry Res 2011, 189(3):385-391.

33. McLean CP, Anderson ER: Brave men and timid women? A review of the gender differences in fear and anxiety. Clin Psychol Rev 2009, 29(6):496-505.

34. Soni $\mathrm{M}$, Curran $\mathrm{VH}$, Kamboj SK: Identification of a narrow post-ovulatory window of vulnerability to distressing involuntary memories in healthy women. Neurobiol Learn Mem 2013, 104:32-38.

35. Liu N, Zhang F, Wei C, Jia Y, Shang Z, Sun L, Wu L, Sun Z, Zhou Y, Wang Y et al: Prevalence and predictors of PTSS during COVID-19 outbreak in China hardest-hit areas: Gender differences matter. Psychiatry Research 2020, 287.

36. Felmingham K, Williams LM, Kemp AH, Liddell B, Falconer E, Peduto A, Bryant R: Neural responses to masked fear faces: sex differences and trauma exposure in posttraumatic stress di sorder. J Abnorm Psychol 2010, 119(1):241-247.

37. Essau CA, Lewinsohn PM, Seeley JR, Sasagawa S: Gender differences in the developmental course of depression. Journal of affective disorders 2010, 127(1-3):185-190.

38. Felton JW, Cole DA, Martin NC: Effects of rumination on child and adolescent depressive reactions to a natural disaster. the 2010 Nashville flood. Journal of abnormal psychology 2013, 122(1):64-73.

39. Sullivan G, Vasterling JJ, Han X, Tharp AT, Davis T, Deitch EA, Constans JI: Preexisting mental illness and risk for developing a new disorder after hurricane Katrina. The Journal of nervous and mental disease 2013, 201(2):161-166.

40. Giannopoulou I, Strouthos M, Smith P, Dikaiakou A, Galanopoulou V, Yule W: Post-traumatic stress reactions of children and adolescents exposed to the Athens 1999 earthquake. European psychiatry : the journal of the Association of European Psychiatrists 2006, 21(3):160-166.

41. Sahin NH, Batigun AD, Yilmaz B: Psychological symptoms of Turkish children and adolescents after the 1999 earthquake: exposure, gender, location, and time duration. Journal of traumatic stress 2007, 20(3):335-345. 